\title{
A statistical model for predicting the inter-annual variability of birch pollen abundance in Northern and North-Eastern Europe
}

\author{
Olga Ritenberga ${ }^{\mathrm{a}, *}$, Mikhail Sofiev $^{\mathrm{b}}$, Pilvi Siljamo $^{\mathrm{b}}$, Annika Saarto $^{\mathrm{c}}$, Aslog Dahl $^{\mathrm{d}}$, Agneta Ekebom $^{\mathrm{e}}$,
} Ingrida Sauliene ${ }^{\mathrm{f}}$, Valentina Shalaboda ${ }^{\mathrm{g}}$, Elena Severova ${ }^{\mathrm{h}}$, Lucie Hoebeke ${ }^{\mathrm{i}}$, Hallvard Ramfjord ${ }^{\mathrm{j}}$

a University of Latvia Faculty of Geography and Earth Sciences, Rainis bvld 19, Riga, LV -1586, Latvia

${ }^{\mathrm{b}}$ Finnish Meteorological Institute, Erik Palmenin aukio 1, 00560 Helsinki, Finland

c Unit of Aerobiology, University of Turku, Finland

${ }^{\mathrm{d}}$ Department of Biological and Environmental Sciences, University of Gothenburg, Sweden

e Palynological Laboratory, Swedish Museum of Natural History, Stockholm, Sweden

${ }^{\mathrm{f}}$ Research Institute, Siauliai University, Siauliai, Lithuania

${ }^{g}$ Institute for Experimental Botany of the NAS of Belarus, Minsk, Belarus

${ }^{\text {h }}$ Moscow State University, Moscow, Russian

${ }^{i}$ Belgian Aerobiological Network, Mycology and Aerobiology service, Scientific Institute of Public Health, Brussels, Belgium

${ }^{\mathrm{j}}$ Department of Biology, Norwegian University of Science and Technology, Trondheim, Norway

\section{H I G H L I G H T S}

- New model for predicting seasonal pollen index for large regions is developed.

- Procedure of cluster analysis-based region selection is proposed.

- A single universal equation describes the next year seasonal pollen index.

- Combination biological and meteorological factors shows the best predicting capacity.

- The model was tested for Russia and Belgium to identify the limits of the method.

\section{A R T I C L E I N F O}

\section{Article history:}

Received 22 June 2017

Received in revised form 7 September 2017

Accepted 7 September 2017

Available online 30 September 2017

Editor: P Elena Paoletti

\section{Keywords:}

Seasonal pollen index

Birch pollen

Inter-annual variability

Pollen forecasting
G R A P H I C A L A B S T R A C T

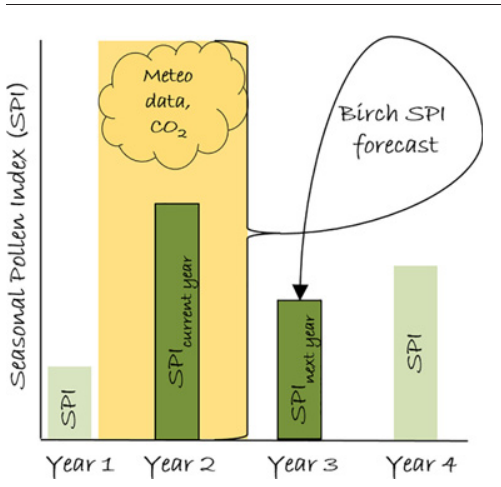

A B S T R A C T

The paper suggests a methodology for predicting next-year seasonal pollen index (SPI, a sum of daily-mean pollen concentrations) over large regions and demonstrates its performance for birch in Northern and North-Eastern Europe. A statistical model is constructed using meteorological, geophysical and biological characteristics of the previous year). A cluster analysis of multi-annual data of European Aeroallergen Network (EAN) revealed several large regions in Europe, where the observed SPI exhibits similar patterns of the multi-annual variability. We built the model for the northern cluster of stations, which covers Finland, Sweden, Baltic States, part of Belarus, and, probably, Russia and Norway, where the lack of data did not allow for conclusive analysis. The constructed model was capable of predicting the SPI with correlation coefficient reaching up to 0.9 for some stations, odds ratio is infinitely high for $50 \%$ of sites inside the region and the fraction of prediction falling within factor of 2 from observations, stays within 40-70\%. In particular, model successfully reproduced both the bi-annual cycle of the SPI and years when this cycle breaks down.

(c) 2017 Elsevier B.V. All rights reserved.

\section{* Corresponding author.}

E-mail addresses: olga.ritenberga@lu.lv (O. Ritenberga), mikhail.sofiev@fmi.fi (M. Sofiev), pilvi.siljamo@fmi.fi (P. Siljamo), annika.saarto@utu.fi (A. Saarto), aslog.dahl@bioenv.gu.se (A. Dahl), agneta.ekebom@nrm.se (A. Ekebom), ingrida.sauliene@su.lt (I. Sauliene), shalaboda_valya@mail.ru (V. Shalaboda), elena.severova@mail.ru (E. Severova),

lucie.hoebeke@wiv-isp.be (L. Hoebeke), hallvard.ramfjord@ntnu.no (H. Ramfjord). 


\section{Introduction}

One of the most-important parameters quantifying the strength of an allergenic pollen season is a Seasonal Pollen Index, SPI, which is defined as a sum of all daily-mean pollen concentrations, i.e. a seasonlong integral of pollen concentrations. It was related to severity of human allergy (Bastl et al., 2016; D'Amato et al., 2007; Huynen et al., 2003), used as an indicator of the productivity of trees, such as olives (Galán et al., 2014; Myszkowska, 2013; Orlandi et al., 2005; Oteros et al., 2013; Prasad and Craufurd, 1999), as well as predictive parameter for the wine (Cunha and Ribeiro, 2015) or olives (Dhiab et al., 2016) production and as a bio indicator of plant reaction to the on-going climate change (Hatfield and Prueger, 2015; Hedhly et al., 2009; Storkey et al., 2014; Zhang et al., 2014). Apart from that, the SPI is used in numerous pollen forecasting models as a scaling factor determining the predicted pollen concentrations (Helbig et al., 2004; Prank et al., 2013; Puc, 2012; Ranta et al., 2008; Ritenberga et al., 2016; Siljamo et al., 2012; Sofiev et al., 2012; Stach et al., 2008; Toro et al., 1998; Veriankaitè et al., 2009; Zhang et al., 2013; Ziello et al., 2012).

The SPI is known to change substantially from year to year depending on combination of meteorological factors and physiology of the plant (Masaka, 2001; Ranta and Satri, 2007), see also a review of Dahl et al. (2013). Such variability, for some trees (e.g., birch), exhibits a quasi-bi-annual behaviour (a strong year is followed by a weak one and vice versa), which however, is broken in some years (Dahl and Strandhede, 1996; Detandt and Nolard, 2000; Grewling et al., 2012; Hättestrand et al., 2008; Jato et al., 2007; Latałowa et al., 2002). This behaviour was attributed by Dahl and Strandhede (1996) to a combination of meteorological and physiological factors, who suggested that neither meteorology nor the innate biannual behaviour is decisive, but rather a combination of both. Indeed, since catkin development is expensive, their abundance takes a large toll of carbohydrates from the annual shoot and impedes the expansion of leaves, thus limiting the amount of photosynthesis products available for development of the next year catkins. This cycle can be interrupted if weather is, for instance, strongly favourable allowing the smaller leaves to assimilate efficiently. Then flowering can be strong for two years in a row.

The same variability tends to occur synchronously in several plants, such as birch, alder and hazel, and over large regions (Ranta and Satri, 2007; Šaulienè et al., 2014). Such synchronization also suggests strong influence of meteorology as the only common factor for different plants distributed over large areas.

Apart from the strong inter-annual variability, several wind pollinated trees, such as birch, olives, oak, etc. have positive long-term trend of the SPI (Garcia-Mozo et al., 2014; Yli-Panula et al., 2009; Prank et al., 2013; Severova and Volkova, 2016; Spieksma et al., 2003, 1995). These trends were attributed to changing climatic conditions and/or to increasing abundance of the plants. Among measurable indicators of these factors, one can consider the growing level of $\mathrm{CO}_{2}$ in the atmosphere and trends in the regional leaf area index. Thus, several studies showed that with higher level of $\mathrm{CO}_{2}$, plants tend to produce more pollen (Ladeau and Clark, 2006; Zhang et al., 2015; Ziska et al., 2001; Ziska and Beggs, 2012).

Among the meteorological factors affecting the intensity of the trees flowering, temperature and precipitation amount of the preceding year are the most-commonly mentioned (Yli-Panula et al., 2009). One can therefore expect that the regional synchronization of the SPI behaviour takes place at least at synoptic scale, i.e. $10^{2}-10^{3} \mathrm{~km}$ and this very scale should be considered when developing models for the SPI. However, most of studies consider it at shorter scales using one or few closelylocated sites (Corden et al., 2002; Dahl and Strandhede, 1996; Grewling et al., 2012; Severova and Volkova, 2016).

Many of the above studies completed the analysis of the SPI interannual behaviour with statistical models aiming at predicting the next-year SPI using the previous-year SPI and meteorology. The procedure of constructing such models usually started from log- or square- root (sqrt-) transform of the SPI followed by multi-linear regression fitting. The input parameters usually included in the analysis are mean temperature of various time intervals (one study took heat sum over certain periods) and the previous-year SPI. However, no systematic pre-processing of the input parameters was performed, and all models were built for individual locations, even if the study was considering several sites.

The current study addresses the above-outlined omissions and aims at construction of a predictive model for birch SPI over large regions in Europe. We will propose a simple procedure for delineating such areas and build the model for the northern region.

\section{The working hypotheses}

We assume that the SPI is a regional parameter determined by the synoptic-scale meteorological processes, i.e. a few hundreds of kilometres. It should therefore be possible to identify the regions that react synchronously and demonstrate similar patterns of the SPI yearto-year variations. The corresponding temporal scale is from several days up to 1-2 weeks - this will be the maximum temporal resolution of the input data, i.e. we shall not be interested in individual meteorological events.

Secondly, absolute values of the SPI are of essentially no importance: they are decided by vegetation density in proximity to the station, which is a static parameter. Therefore, spatial and temporal variations inside these regions are separable.

With the above assumptions, it should be possible to construct a statistical model for the SPI variation over these regions taken as "boxes", i.e. not resolving individual stations but taking each region as a single entity with the normalised SPI averaged over the region.

\section{Materials and methods}

\subsection{Study area}

The study was focused over the region between the latitudes $50^{\circ} \mathrm{N}$ and $70^{\circ} \mathrm{N}$ and longitudes from $5^{\circ} \mathrm{E}$ to $40^{\circ} \mathrm{E}$, Birch pollen data from 15 aerobiological sites were included in the analysis.

The analysed region has moderate maritime climate with cold winters and moderate summers. Birch fraction reaches up to $30 \%$ of the total forest coverage (see maps in (Ritenberga et al., 2016; Sofiev et al., 2006)).

\subsection{Airborne pollen concentrations}

Birch pollen data were extracted from the database of European Aeroallergen Network (EAN). Pollen sampling was performed using Burkard or Lanzoni 7-days volumetric trap (Hirst, 1954). Pollen was identified with optical microscopy, using country-specific (random, vertical, horizontal traverses) counting technique but generally following the aerobiological standards (Galán et al., 2014). For each year, the SPI was computed as an integral of concentrations over the whole observed period. The length of time series varied from station to station, reaching 40 years (19742015) for a few sites. The varying length of observations created evident challenges for processing and interpretation of the obtained results. However, under the assumption of internal homogeneity of the SPI variation within the region, verified in the next section, all stations are normalised and averaged into the regional mean, thus reducing the problem to a different sampling volume in different years. Additionally, all time series shorter than 11 years were filtered out (Table 1). No other thinning of the dataset was possible due to the limited number of sites (15, as shown in Table 1 and Fig. 1 ). 


\subsection{Meteorological data, $\mathrm{CO}_{2}$ and $\mathrm{LAI}$}

A wide list of parameters potentially governing the regional birch SPI was created based on literature analysis and general considerations.

\subsubsection{Meteorological information}

The most-frequently mentioned meteorological factors influencing the seasonal pollen index are temperature and precipitation rates (Dahl and Strandhede, 1996; Yli-Panula et al., 2009; Latałowa et al., 2002). It was decided to use also related parameters, such as solar short wave radiation and accumulated heat amount (heat sum), with care taken against mutual correlation of these parameters as descried in the next section. The meteorological data were taken from the European Re-analysis ERA-Interim dataset (Dee et al., 2011; Simmons et al., 2010). Temporal resolution of the data was $3 \mathrm{~h}$ with spatial grid of $0.72^{\circ} \times 0.72^{\circ}$. The meteorological data covered the period from 1980 to 2015 , which thus limited the analysed period to these 36 years. As seen from Table 1, the sampling network of the region was limited during 1980s to 4 locations, expanding over 10 sites only after 2000.

Heat sum (1) is calculated from daily mean temperature following the approach of the SILAM model (Sofiev et al., 2012), which suitability for local-scale computations was confirmed by modelling in Riga (Ritenberga et al., 2016).

$H(d)=\sum_{d=d_{s}}^{D}\left[\overline{T(d)}-T_{c-o}\right]_{+}$

Here, $H$ is temperature sum (heat sum), with units of degree day $\left(\mathrm{C}^{\circ} /\right.$ day); $d$ is the day of $H$ calculation; $d_{s}$ - starting day of the heat accumulation - 1 st of March in this case; $T(d)$ - daily temperature, ${ }^{\circ} \mathrm{C} ; T_{c-o}$ - cutoff temperature (temperatures below this threshold are not summed up), ${ }^{\circ} \mathrm{C},[\mathrm{x}]_{+}$is the function that equals 0 for $\mathrm{x}<0$ and 1 for $\mathrm{x} \geq 0$ (it excludes the temperatures below the cut-off level).

The same cut-off temperature of $3.5^{\circ} \mathrm{C}$ was used for the heat sum calculations for all monitoring sites in the region (Sofiev et al., 2012), justification for accepting a value of $3.5^{\circ} \mathrm{C}$ is described by Ritenberga et al. (2016) and Siljamo et al. (2012).

\subsubsection{Leaf area index}

Leaf area index (LAI) was included in the data analysis as one of possible predictors for the SPI. It was hypothesised that there could be a relationship (straight or inverse) between the annual production of pollen and the LAI. An indirect support of this consideration is that the pollen data are used for the LAI reconstruction in palynological studies (Williams et al., 2008). Data of the LAI were taken from a global reanalysis of the vegetation phenology (Stckli et al., 2011), which contains daily $1^{\circ} \times 1^{\circ}$ LAI maps for the whole study period. For our purposes, they were aggregated to monthly level.

\subsubsection{Carbon dioxide}

Carbon dioxide $\left(\mathrm{CO}_{2}\right)$ is one of the factors, possibly influencing the annual amount of pollen from various taxa (Albertine et al., 2014). Carbon dioxide has a well-expressed positive trend during at least last 40 years, somewhat resembling the trends in the birch pollen abundance. The $\mathrm{CO}_{2}$ data used for the analysis were downloaded from the NOAA Earth System Research Laboratory (ESRL) public archive (Ed Dlugokencky and Pieter Tans, NOAA/ESRL (www.esrl.noaa.gov/gmd/ ccgg/trends/) for the years from 1980 to 2015.

\subsubsection{Seasonal pollen index}

The SPI (Y-1) of the preceding year was included to account for the plant state and behaviour in the past.

\section{Model construction}

\subsection{Region selection}

The SPI time series observed at EAN stations with $>11$ years of data (taken both from within the target region and from the stations outside) were correlated with each other and clustered with regard to the pairwise correlation coefficient $r$. Despite not satisfying the rigorous definition of distance, this parameter has two vital features: (i) it does not depend on absolute SPI values at the stations, and (ii) it is of correct monotonicity, i.e. shows the stations with similar inter-annual variations as close ones.

The clustering procedure also requires definition of the reference point, against which all other stations are positioned. We used the Turku station in Finland, which: (i) possesses one of the longest time

Table 1

Availability of birch pollen data for analysis of Northern, North-Eastern Europe regional data set sites (grey - data available; black - data suitable for analysis).

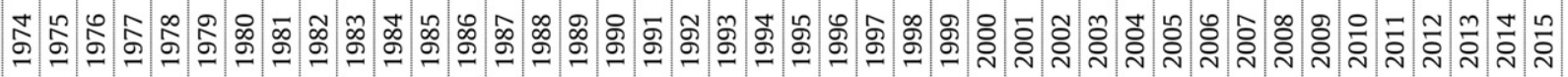

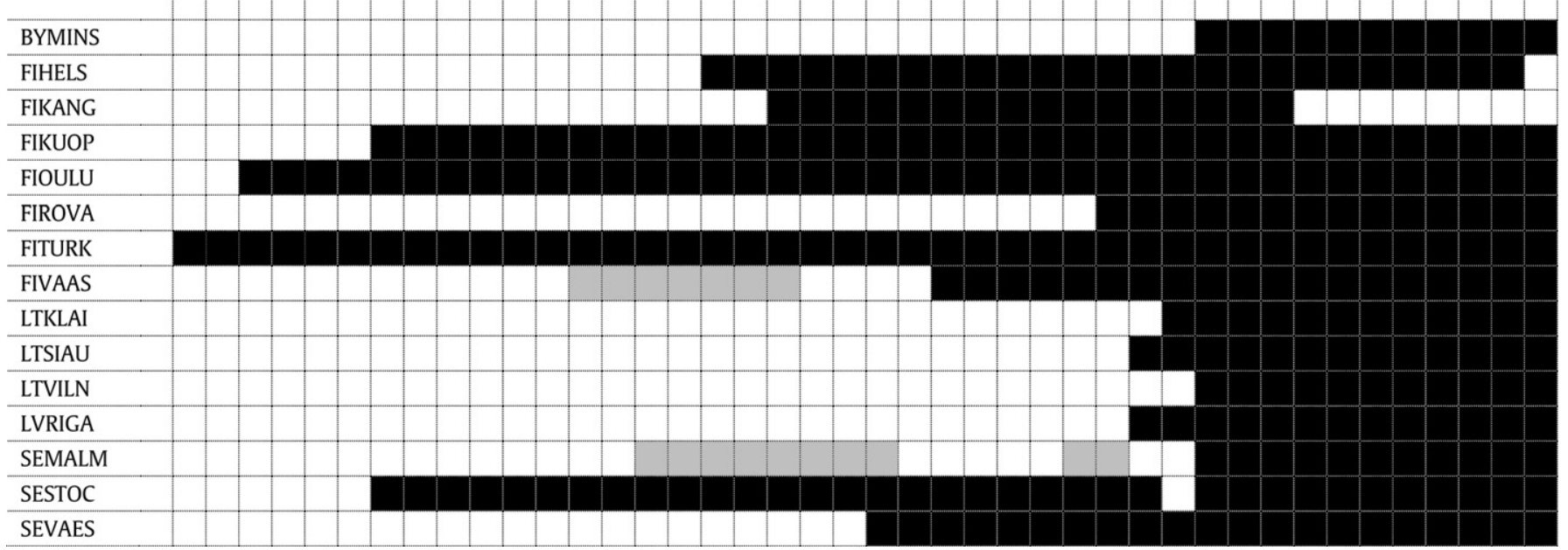




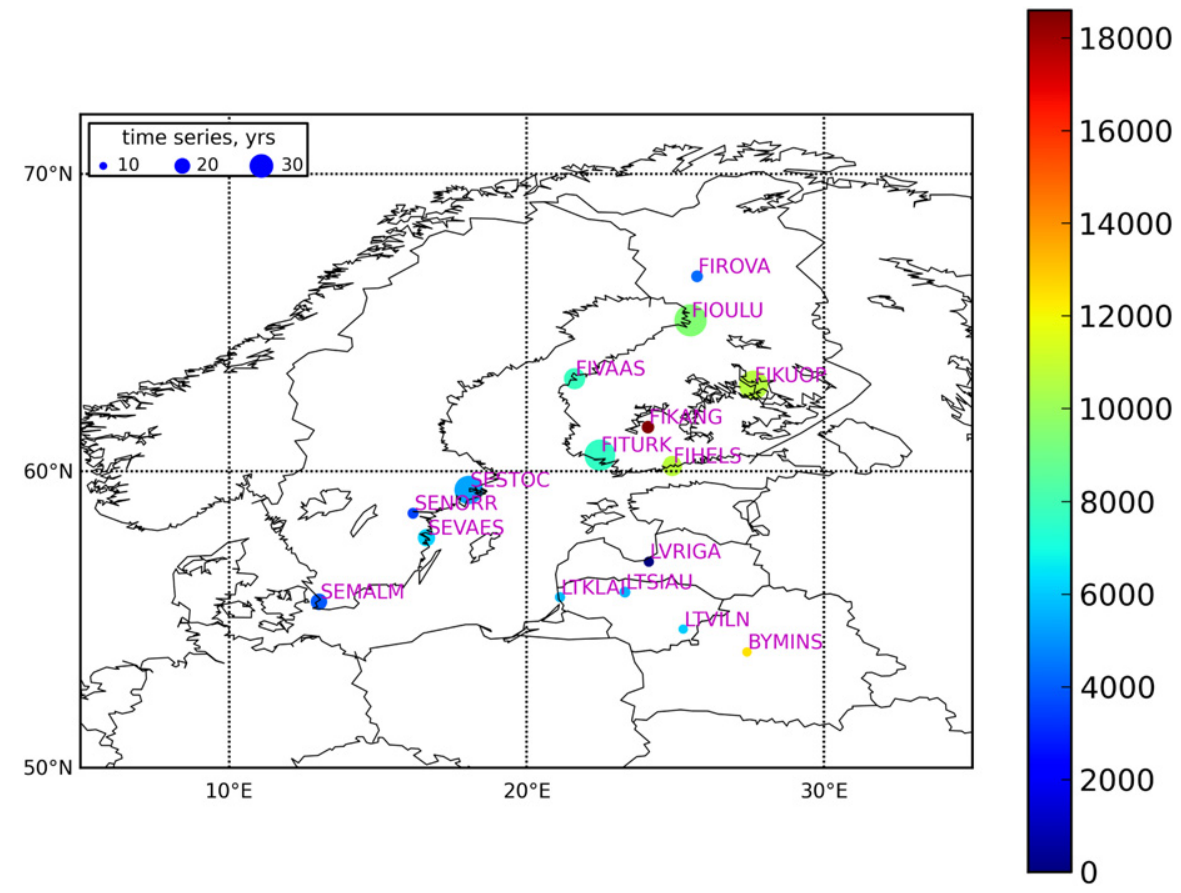

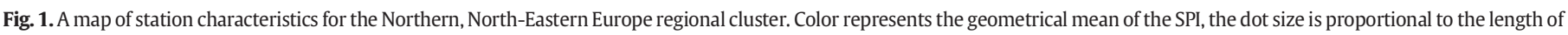
the time series, provided in Table 1.

series in EAN fully covering the study period, (ii) is conveniently located in the middle of the region with comparatively dense pollen network, (iii) shows strong SPI variability, (iv) shows high absolute birch pollen concentrations, thus making the problem important from allergological point of view, (v) is located in the climate-sensitive area: the temperature rise in Finland due to climate change is much higher than the global average (Hartmann et al., 2013), which can have its fingerprints in the SPI trends.

The correlation matrix was analysed and only site pairs with $r>0.85$ and $p<0.01$ were retained in the cluster (Table 2). The resulting cluster of stations, hereinafter referred as the Northern, North-Eastern Europe regional data set, included aerobiological stations of Finland (Helsinki (FIHELS), Kangasala (FIKANG), Kuopio (FIKUOP), Oulu (FIOULU), Rovaniemi (FIROVA), Turku (FITURKU), Vaasa (FIVAAS)), Lithuania (Klaipeda (LTKALI), Siauliai (LTSIAU), Vilnius (LTVILN)), Latvia (Riga (LVRIGA)), Belarus (Minsk (BYMINS)), Sweden (Stockholm (SESTOC),
Malmö (SEMALM), Vaestervik (SEVAES)), totally 15 stations with $>11$ years of data (Fig. 1). Long- term observations are available from Finland (data from 7 stations) and Sweden (3 stations), whereas the stations from Belarus, Lithuania, and Latvia have from 11 up to 20 years of data.

As a result of this procedure, the area of the region for analysis gets clear: it covers the above countries and possibly extends further to the east, where no stations are available all the way down to Moscow, which is outside the cluster. Western border is also somewhat unclear: in Norway, only NOTRON in central part of the country satisfies the requirement on the time series length - and is outside the cluster, probably because of strong dominance of Atlantic Ocean in the weather pattern.

As shown in Table 1, sampling of the region evolves with time, with its southern part practically not represented in early years. However, the existing time series are sufficient for establishing the statistically

Table 2

Correlation matrix of SPI for the Northern, North-Eastern Europe regional data set.

\begin{tabular}{|c|c|c|c|c|c|c|c|c|c|c|c|c|c|c|c|}
\hline & BYMINS & FIHELS & FIKANG & FIKUOP & FIOULU & FIROVA & FITURK & FIVAAS & LTKLAI & LTSIAU & LTVILN & LVRIGA & SEMALM & SESTOC & SEVAES \\
\hline BYMINS & 1 & 0.66 & 0.95 & 0.61 & 0.74 & 0.84 & 0.8 & 0.69 & 0.78 & 0.70 & 0.69 & 0.49 & 0.79 & 0.87 & 0.95 \\
\hline FIHELS & & 1 & 0.91 & 0.87 & 0.90 & 0.83 & 0.93 & 0.89 & 0.91 & 0.97 & 0.89 & 0.83 & 0.87 & 0.85 & 0.69 \\
\hline FIKANG & & & 1 & 0.92 & 0.91 & 0.84 & 0.96 & 0.79 & 0.99 & 0.78 & 0.97 & 0.67 & 0.80 & 0.92 & 0.84 \\
\hline FIKUOP & & & & 1 & 0.85 & 0.85 & 0.76 & 0.86 & 0.87 & 0.91 & 0.88 & 0.94 & 0.75 & 0.77 & 0.66 \\
\hline FIOULU & & & & & 1 & 0.89 & 0.8 & 0.79 & 0.94 & 0.86 & 0.95 & 0.83 & 0.78 & 0.79 & 0.71 \\
\hline FIROVA & & & & & & 1 & 0.90 & 0.81 & 0.82 & 0.79 & 0.80 & 0.80 & 0.73 & 0.77 & 0.75 \\
\hline FITURK & & & & & & & 1 & 0.92 & 0.86 & 0.89 & 0.86 & 0.79 & 0.84 & 0.86 & 0.85 \\
\hline FIVAAS & & & & & & & & 1 & 0.86 & 0.94 & 0.85 & 0.87 & 0.67 & 0.83 & 0.74 \\
\hline LTKLAI & & & & & & & & & 1 & 0.96 & 0.96 & 0.82 & 0.92 & 0.94 & 0.79 \\
\hline LTSIAU & & & & & & & & & & 1 & 0.94 & 0.85 & 0.88 & 0.89 & 0.72 \\
\hline LTVILN & & & & & & & & & & & 1 & 0.83 & 0.91 & 0.93 & 0.78 \\
\hline LVRIGA & & & & & & & & & & & & 1 & 0.60 & 0.70 & 0.57 \\
\hline SEMALM & & & & & & & & & & & & & 1 & 0.82 & 0.72 \\
\hline SENORR & & & & & & & & & & & & & & 0.91 & 0.78 \\
\hline SESTOC & & & & & & & & & & & & & & 1 & 0.93 \\
\hline SEVAES & & & & & & & & & & & & & & & 1 \\
\hline
\end{tabular}


significant high correlation between all sites in the region, which justifies the consideration of the "regional mean SPI variability", unified over the whole period. The next section describes the transformations used to obtain the single 36-years-long regional time series set for further analysis.

\subsection{Target variable transformation: Normalization of the SPI distribution, regionalization}

The raw pollen data have several features, which make construction of an efficient statistical model problematic - see discussion in Ritenberga et al. (2016). Integration over the season towards SPI reduces some of the problems, e.g., the non-stationarity of the time series. However, several data pre-processing steps are still required prior to the model construction.

The $S P I_{i}$ of each station $i$ for the particular year $Y$ should be normalised with its multi-annual geometric mean $\mathrm{SP}_{l}^{\text {geomean }}$ taken over the whole observed period of the station (represented by color in the Fig. 1), thus eliminating the dependence on local birch abundance and making all sites within the region comparable (Fig. 2, panels a and b):

$\operatorname{SPI}_{i}^{\text {norm }}(Y)=\frac{\operatorname{SPI}_{i}(Y)}{\operatorname{SPI}_{i}^{\text {geomean }}}$

Since the distribution density of the $S P I_{i}^{\text {morm }}$ is closer to log-normal than to normal, we applied logarithmic transformation, finally arriving at the deviation $\triangle \operatorname{SPI}_{i}^{N}(Y)$ of the normalised annual $S P_{i}$ for each year $Y$ from its long-term geometric mean value (Fig. 2, panel c).

According to the working hypothesis supported by the correlation analysis above, the same processes control the SPI behaviour at all stations within the selected region. Therefore, one should consider their SPI series $\Delta \operatorname{SPI}_{i}^{N}(Y)$ as realizations of the single stochastic process the regional time series $\Delta S P T^{r e g}(Y)$, - which effective and unbiased estimation is arithmetic mean over the cluster.

\subsection{Input data transformation}

Upon turning the SPI time series into normally-distributed deviations from the long-term mean levels, corresponding transformations should be applied to the input data as well: they should be converted into deviations with near-normal distribution type, the approach analogous to (Ritenberga et al., 2016) but with the SPI as the target variable.

\subsubsection{Selection of the time axis}

According to the above-mentioned studies, only meteorological conditions during specific phenological phases affect the next-year SPI. One needs therefore to delineate the corresponding periods. Astronomical time used in those studies is an inconvenient variable since it ignores difference between the years and thus tends to mix-up the phenological phases. It also ignores the difference in the flowering time across the region. Therefore, again following (Ritenberga et al., 2016) approach, we selected the heat sum as the phenologically-relevant variable for the time axis.

The challenge of the regional consideration is that even expressed via heat sum, the phenological phases still occur at different moments: the further to the north the less heat is needed for the season progression (Sofiev et al., 2012). To overcome this difficulty, we express the time scale in \% of the total heat accumulated during the whole year, normalised to its long-term mean value, at each station. Annual heat sum differs by up to a factor of two between the aerobiological stations within the region, whereas, e.g., the heat sum threshold for flowering expressed in relative terms is nearly constant - see (Supplementary material 1 - “Annual_cumulative_heat_sum_in_2010”) of (Sofiev et al., 2012) with the data source of ERA-Interim and degree day as unit. The idea of this transformation goes back to (Linsser, 1867), who demonstrated it for pine.

For the normalised heat sum, the year was split to 6 periods representing different fractions of the annual heat sum: 0-0.05 (preseason before the flowering starts); $0.05-0.13$ (flowering season); the three post-season intervals: $0.13-0.25 ; 0.25-0.45$; the whole postflowering period with shorter end $0.13-0.4$; and the whole period from start of heat sum accumulation until the end of active vegetation was taken as a single time slot $0.0-0.45$. The selection of the periods was based on preliminary calculations of the heat scale for Turku and Riga.

\subsubsection{Conversion of the input meteorological data into deviations}

The deviation of the regional $\Delta S P I^{r e g}(Y)$ from its long-term mean should be related to the normalised meteorological variables, also taken as deviations. The transformation was made station- and variable- wise and included:

(i) calculation of variable deviation from the long-term mean value, for each year, each site, during each of the above heat sum intervals; Since this step does not involve pollen data there is no limitations due to the data availability. The meteorological data are taken from ERA-Interim and the whole period 1980-2015 is used without omissions;

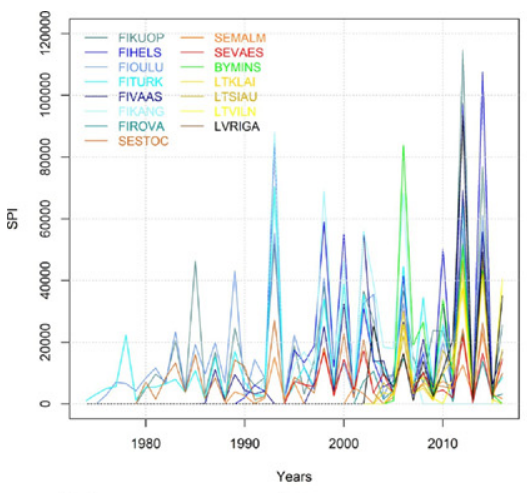

(a) initial time series, $\Sigma$ pollen /yearm-3]

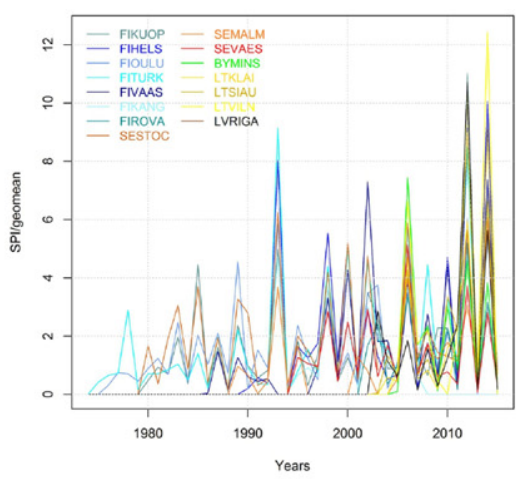

(b) normalized station-wise with multi-annual geometric mean, [relative unit]

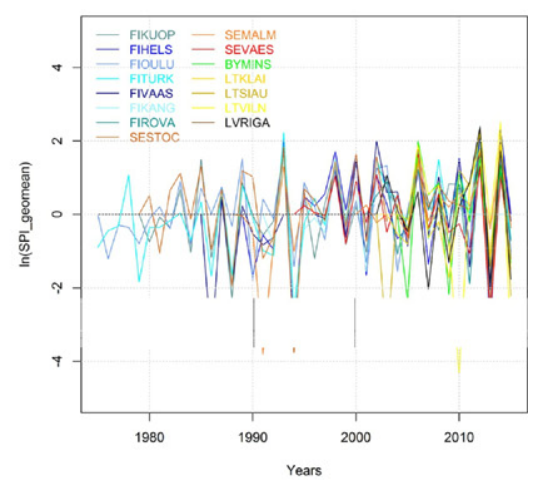

(c) SPI normalized deviation: logarithm of the time series panel (b), [relative unit]

Fig. 2. Transformation of the SPI observations for the stations in the Northern, North-Eastern Europe regional data set. 
(ii) spatial averaging of deviations across the region, for each year. As in the step (i), all years 1980-2015 were taken into consideration. As a result, we obtain the regional set of predictors: regional deviations of the environmental parameters from their longterm average, for each of the six heat sum intervals during each year.

\subsubsection{Physical parameters describing the long-term trends}

No transformations were applied to of $\mathrm{CO}_{2}$ and $\mathrm{LAI}$ in order to preserve their properties: $\mathrm{CO}_{2}$ has a well-expressed trend during the last 40 years and LAI reflects the annual changes in the vegetation of the region (Supplementary material 2, Supplementary material 3). Both parameters monthly data were simply averaged for each year.

\subsection{Construction of predictive SPI model}

Very limited size of the dataset (only one regional time series comprised of 15 individual time series of varying length) did not allow splitting the stations to learning and control datasets. Therefore, the regional-model coefficients were obtained using bootstrap method and multi linear regression (MLR).

At the first step, MLR was made against a complete set of meteorological parameters listed above, taken for all 6 time intervals during the year $Y$ (the year to predict) and the year $Y-1$ (previous year), in order to identify statistically significant predictors. Expectedly, predictors from the previous year $Y-1$ showed larger influence on the SPI of the year $Y$ than those from the year $Y$. From 21 predictors ( 6 different periods for temperature, solar radiation, precipitation; $\mathrm{CO}_{2}$; $\mathrm{LAI}$; SPI all for the year Y-1), the following parameters from $Y-1$ were identified as potentially useful:

- precipitation $P r_{0.13}$ for the period 0.13-0.25 of the annual heat sum accumulation

- temperature $T_{0.13}$ for the period $0.13-0.25$, of the annual heat sum accumulation

- temperature $T_{0.25}$ for the period 0.25 to 0.45 of the annual heat sum accumulation

- short wave solar radiation $S W_{0}$ for the period from 0 to 0.05 of the annual heat sum accumulation

$-\mathrm{SPI}_{\mathrm{Y}-1}$

$-\mathrm{CO}_{2} \mathrm{Y}-1$

All further analysis uses only these 6 parameters.

The bootstrap included 15 iterations, one for each of 15 station datasets withheld from both regional SPI and regional meteorological averaging. The SPI data and meteorological parameters for the remaining stations were averaged over the region. After that, the multilinear regression was calculated obtaining the model coefficients for the regional time series with one site excluded.

The fitting coefficients were averaged across the iterations, finally obtaining the mean regression coefficients and their standard deviation.

The procedure was repeated with and without previous-year $S P I_{Y-1}$ in the list of possible predictors.

\section{Results: models for SPI in Northern, North-Eastern Europe}

\subsection{Model with meteo-only input}

During the data analysis, we realized that it is possible to build the model using only available meteorological data and the trenddescribing variable $\mathrm{CO}_{2, \mathrm{Y}-1}$. This opportunity allows predicting the SPI relative deviation from the long-term mean knowing neither this mean level nor the previous-year SPI. The model becomes detached from the SPI observations and applicable also in places with no aerobiological observations whatsoever.
The regional formula for $\Delta S P I^{r e g}(Y)$ of the year $Y$ based on meteorological data and data of $\mathrm{CO}_{2}$ of the previous year $Y-1$ is:

$$
\begin{aligned}
& \Delta \mathrm{SPI}^{r e g}(Y)=a_{0}+a_{\mathrm{CO}_{2}} \mathrm{CO}_{2, Y-1}+a_{p r} P_{0.13}+a_{s w} S w_{0}+a_{T_{0.13}} T_{0.13} \\
& +a_{T_{0.25}} T_{0.25}
\end{aligned}
$$

The mean values of the intercept $a_{0}$ and other coefficients are shown in Table 3, first row.

The obtained model is not perfect (see evaluation section) but its independence from pollen observations makes it a very important instrument for assessment of the SPI variability.

\subsection{Model with full set of variables; accounting for the different statistical significance}

Adding $S P_{Y-1}$ as a predictor significantly increases the quality of the model. The final formula includes the same meteorological parameters as the meteo-only model, $\mathrm{CO}_{2}$ and SPI from the previous year (Table 3, second row).

There are two parameters of Eq. (3) with noticeably lower statistical significance than the others ( $p$-value $0.05-0.1$ ): precipitation $\operatorname{Pr}$ and $T_{0.25}$. Their importance was evaluated by removing them from the data set and constructing the model based only on predictors of high statistical significance (Table 3, last row).

\subsection{Evaluation of the constructed models}

The evaluation of the three models of the Table 3 followed several pathways and was performed for both entire region (i.e. the learning dataset) and for each station in the cluster. There are several parameters used for the evaluation, including both "standard" statistics and threshold-based ones. Efficiency of the standard statistics was however hampered by the limited size of the dataset and strongly non-normal distribution of the values. The evaluation approach also took into account the way these models will be applied: for forecasting the nextyear SPI, in particular determining whether it will be high or low year and for forecasting the absolute SPI needed for the modelling.

\subsubsection{Statistics over the whole observed periods}

We consider: (i) Odds Ratio (OR, Fig. 3a) as a measure of differentiating between the high- and low- seasons, (ii) Model Accuracy (MA, Fig. 3b) and (iii) a fraction of the SPI predictions that fall within the factor 2 from the observations (F2, Fig. 3c).

Behaviour of individual stations inside the region differs somewhat but the regional formula tends to work better for the stations with longer time series, i.e. those, which contributed mostly to the model identification (Turku, Kuopio, etc.). The limited size of the dataset and high scores of the models resulted in just few cases of the predictions being wrong. For several sites, the low-high differentiation appeared always correct during the observed years. The sample OR for such sites is infinitely high, shown as $\mathrm{OR}=30$ in Fig. 3a.

The fraction of the predictions falling within the factor of 2 from absolute observations (F2, Fig. 3c) allowed formulating the static persistence-based estimate: the mean SPI at each station (yellow bars in Fig. 3c). The F2 generally stays within $40 \%-70 \%$ being lower only close to the southern edge of the domain. Similarly to other quality measures, the full-parameters and significant-only models showed the highest F2 levels, with meteo-only model staying somewhat behind. The suggested models demonstrated similar or better skills than the persistence approach. One can also see that the northern-most sites FIKEVO and FIROVA tend to be exceptional: at FIROVA, the meteorological information alone was sufficient for good predictions, while FIKEVO was the only site with the highest skills showed by the persistence approach. The reasons for the unusual behaviour of the models are discussed in the next section. 
Table 3

Coefficients (with standard deviation) for regional formula of SPI forecast based on $\mathrm{SPI}_{-1}, \mathrm{CO}_{2}$ and meteorological set.

\begin{tabular}{|c|c|c|c|c|c|c|c|}
\hline & $a_{0}$ & $a_{\mathrm{CO} 2}$ & $a_{P r}$ & $a_{s w}$ & $a_{T 0.13}$ & $a_{T 0.25}$ & $a_{S P I}$ \\
\hline Only meteo and $\mathrm{CO}_{2}$ & $\begin{array}{l}-2 \\
\left( \pm 8 \times 10^{-1}\right)\end{array}$ & $\begin{array}{l}5 \times 10^{-3} \\
\left( \pm 2 \times 10^{-3}\right)\end{array}$ & $\begin{array}{l}6 \times 10^{-2} \\
\left( \pm 7 \times 10^{-3}\right)\end{array}$ & $\begin{array}{l}2 \times 10^{-5} \\
\left( \pm 6 \times 10^{-7}\right)\end{array}$ & $\begin{array}{l}3 \times 10^{-1} \\
\left( \pm 3 \times 10^{-2}\right)\end{array}$ & $\begin{array}{l}3 \times 10^{-1} \\
\left( \pm 3 \times 10^{-2}\right)\end{array}$ & - \\
\hline All predictors & $\begin{array}{l}-4 \\
\left( \pm 7 \times 10^{-1}\right)\end{array}$ & $\begin{array}{l}9 \times 10^{-3} \\
\left( \pm 1 \times 10^{-3}\right)\end{array}$ & $\begin{array}{l}-5 \times 10^{-2} \\
\left( \pm 5 \times 10^{-3}\right)\end{array}$ & $\begin{array}{l}2 \times 10^{-5} \\
\left( \pm 7 \times 10^{-6}\right)\end{array}$ & $\begin{array}{l}2 \times 10^{-1} \\
\left( \pm 1 \times 10^{-2}\right)\end{array}$ & $\begin{array}{l}1 \times 10^{-1} \\
\left( \pm 1 \times 10^{-2}\right.\end{array}$ & $\begin{array}{l}-5 \times 10^{-1} \\
\left( \pm 3 \times 10^{-2}\right)\end{array}$ \\
\hline Only highly significant predictors & $\begin{array}{l}-4 \\
\left( \pm 7 \times 10^{-1}\right)\end{array}$ & $\begin{array}{l}9 \times 10^{-3} \\
\left( \pm 9 \times 10^{-3}\right)\end{array}$ & - & $\begin{array}{l}2 \times 10^{-5} \\
\left( \pm 7 \times 10^{-6}\right)\end{array}$ & $\begin{array}{l}2 \times 10^{-1} \\
\left( \pm 1 \times 10^{-2}\right)\end{array}$ & - & $\begin{array}{l}-5 \times 10^{-1} \\
\left( \pm 3 \times 10^{-2}\right)\end{array}$ \\
\hline
\end{tabular}

- was not included in model.

\subsubsection{Prediction for 2016}

The year 2016 was not included into the model fitting, thus serving for additional, albeit limited, evaluation mimicking the way the model will actually be used: to forecast the next-season severity. The predictions of the models for this year are shown in Fig. 4 (blue, red and yellow columns) together with the long-term mean for each station (shaded area, geometric mean of observed SPI at the site over al years available) and the observed SPI in 2016 (dark green columns). A few stations were excluded from the analysis: FIHELS was moved a few km inland from its historical location, thus making absolute-SPI analysis impossible, whereas the data of FIKANG were not available.

As one can see, 2016 was mostly high-or-normal year over the region: low SPI was recorded only at SEMALM (south-western edge of the region) and LTKLAI (southern edge, near the coast). The meteoonly model was predominantly suggesting moderately-low year, whereas the models including the previous-year SPI suggested high year, in agreement with the observations. The long-term average was a worse predictor than the full-parameters models but evidently was a better than the meteo-only model at the sites where that one predicted low season.

\section{Discussion}

The primary goal of the study was to build the unified model suitable for applications over large regions, thus demonstrating the feasibility of spatial generalization of the SPI predictions using large-scale meteorological features as the controlling parameters. As pointed out in the introduction, the bulk of previous studies concentrated on a single or a few closely-located stations.

The second principal difference of the suggested approach is that we applied a series of non-linear transformations of the input data and changed the governing variable from time to normalised heat sum. These transformations aimed at two targets: (i) sharply reduce the year-to-year variability of temperature accumulation, thus making the seasonal propagation and flower/leaves/seed maturation curves similar for all years; (ii) eliminate also the spatial variability of these curves, thus making them similar for all locations over the considered domain. After that, construction of the predictive models followed standard procedures for multi-component optimal model fitting.

\subsection{Comparison with other approaches}

Since the suggested models are first in their class, direct comparison with published studies is quite difficult. However, certain conclusions can be derived. The most-direct comparison is possible with the study of (Ranta and Satri, 2007), who built three local models for Turku, Kuopio and Oulu stations. Temporal correlation of these models however trails significantly behind the current unified model: it was 0.59 vs 0.82 for Turku and 0.61 vs 0.77 in Oulu. Only in Kuopio, both models scored to 0.65 . The most-probable reason for the higher scores of the current approach is the more comprehensive set of transformations of the data before applying regression.

Similar predicting capacity to that of (Ranta and Satri, 2007) was reported by (Dahl and Strandhede, 1996) but direct comparison is not possible due to sqrt-transformed values reported in that paper. An important difference of that work was that the predictors were taken as heat sums rather than mean temperature over some period, which potentially can further improve the model accuracy.

Quite high correlations of the local SPI and several meteorological drivers were reported for Poznan by (Grewling et al., 2012) but no predictive model were built. The authors also pointed out that they found no parameters capable of explaining the break points in the bi-annual cycle. This study has succeeded but Poznan is outside the current region and the developed models are not directly applicable there.

\subsection{Selection of input parameters}

Among the parameters influencing the SPI, the northern part of Europe is mostly limited by the available heat and solar radiation, so it is not surprising that heat is the most important predictor for our region (Table 3). This is supported by very high scores of the model in the north of Finland (up to 90\%, Fig. 5) and also pointed out by (Ranta et al., 2005). In the south of Europe the stress will probably shift towards water and nutrient availability (Dahl et al., 2013), with Central Europe being arguably the most-difficult to model.

A noticeable degradation of the model skills at the northern-most site FIKEVO is probably caused by the ignored pollen atmospheric transport. Indeed, the characteristic level of the SPI in that region is much lower than in Central Finland and Russia, which makes the local pollen production less important than the impact of the long-distance transport. The transport contribution was estimated by (Sofiev, 2016), who showed that the transport-induced SPI variability grows sharply towards remote regions. This points out at a certain shortcut of the current approach: the developed models should predict the total amount of pollen released from catkins rather than the observed concentrations. The proportionality of these two quantities is not exact and is disturbed by both local pollen dispersion conditions and by the long-range transport (Sofiev, 2016). Averaged over the whole season, the disturbance is comparatively small in the self-polluting regions but can be large if strong remote sources affect the area. The other possible explanation is the genetic differentiation between the birches in far north (mainly Betula nana) and other parts of the domain. The significance of such differentiation was shown for olives by (Chuine and Belmonte, 2004).

\subsubsection{Meteo only model}

An intriguing feature of the current approach differentiating it from the previous studies is that it had produced a comparatively wellperforming model using only meteorological parameters without any reference to the previous-year pollen observations. This is a confirmation of the working hypothesis: meteorology alone controls a large fraction of the SPI variability, synchronously over the whole region.

Performance of the meteo-only model still trails behind the fullinput model, thus suggesting that the biological processes also significantly contribute to the SPI - in agreement with (Dahl and Strandhede, 1996). In particular, the dynamic range of the SPI variability is the largest in the observations, closely followed by the full-input model, whereas the meteo-only model is more conservative (Fig. 5). One can argue then that the plant response serves as an amplifier for the meteorological signals. This also corroborates with conclusions of 


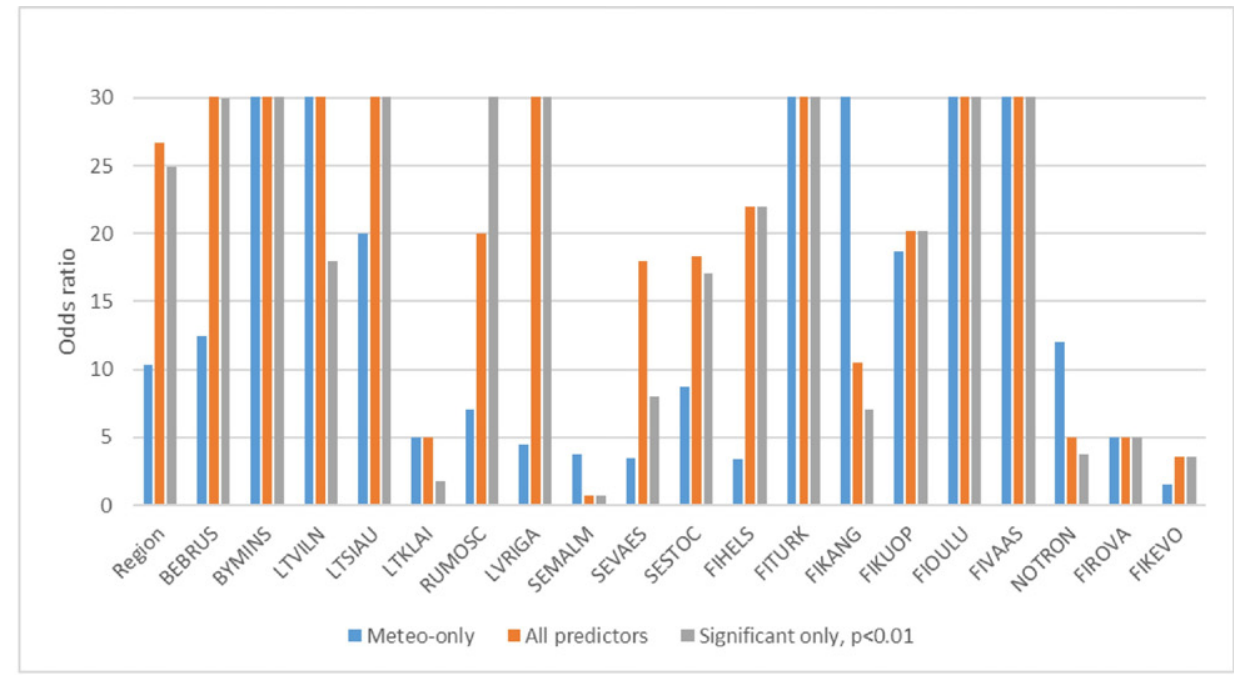

a)Odds ratio for the low-high season predictions by the three models presented in Table 3 (full-set; meteo only, full set with only significant $(\mathrm{p}<0.01)$ predictors). Sites are ordered along the latitude.

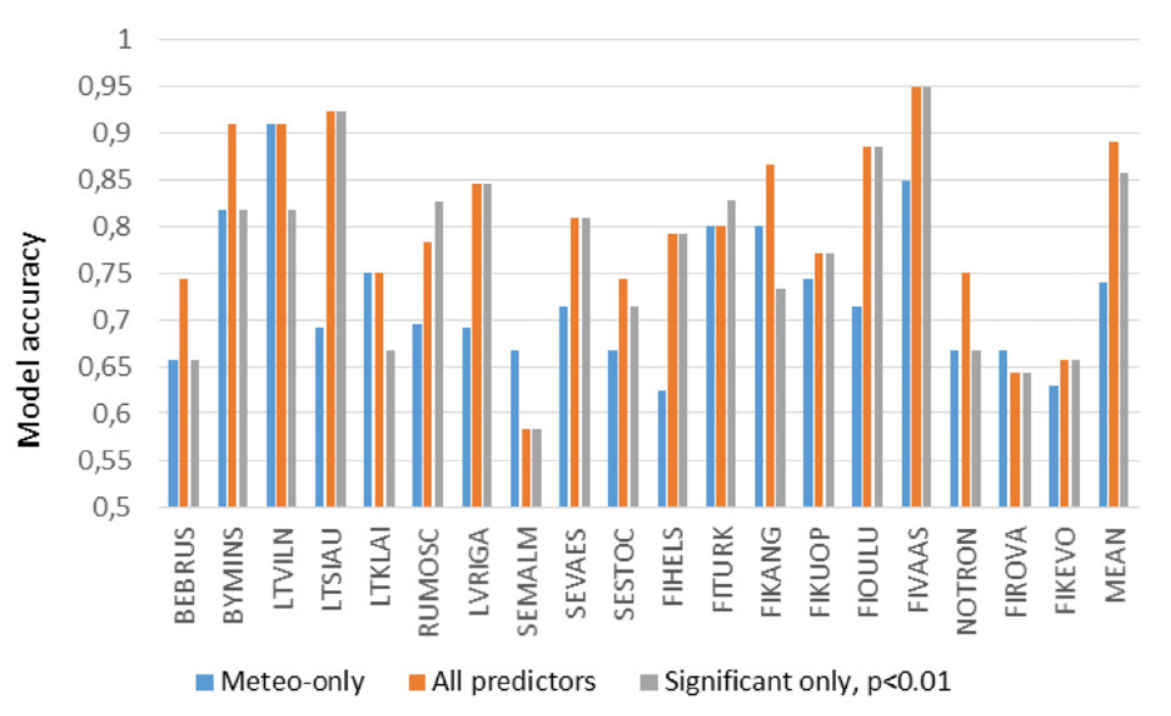

b) Model accuracy (MA) for the low-high season predictions by the three models presented in Table 3 (full- set; meteo only, full set with only significant $(\mathrm{p}<0.01)$ predictors). Sites are ordered along the latitude.

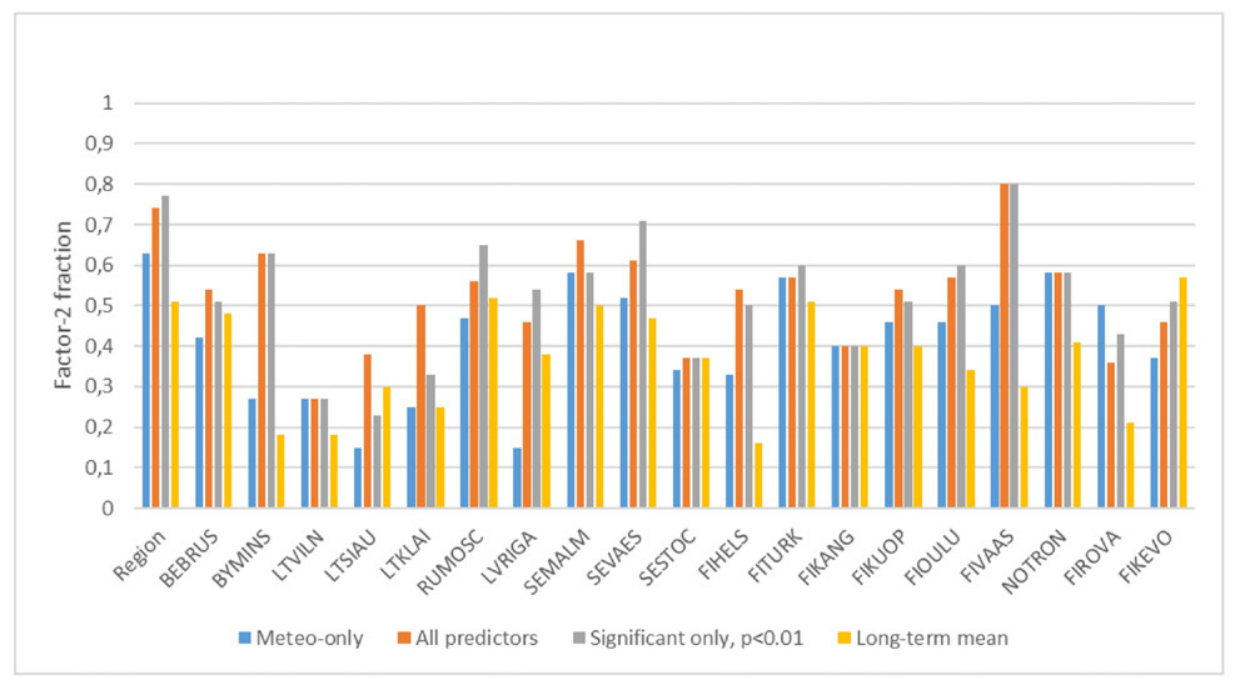

c) Fraction of the SPI predictions within the factor of 2 (F2). Same notations as in c) 3 b.

Fig. 3. Statistics for the constructed models evaluation. 
the biological model (Dahl et al., 2013) that stressed the importance of the combination of meteorological and biological parameters for adequate next-season prediction.

Finally, the meteo-only model reproduces both the bi-annual cycle and the years when it breaks down (Fig. 5), also strongly suggesting that such behaviour of birch is at least inspired by the regional-scale weather phenomena.

\subsubsection{SPI only model}

The second "simplified" model can be built using only SPI but taking it from more than one preceding years. In-essence, it exploits the biannual cycle as the foundation (Ranta et al., 2005; Ranta and Satri, 2007) but can, to a certain extent, adapt to several years without such cycle in sight. In the Baltic countries and Southern Sweden (area $15^{\circ} \mathrm{E}$, $25^{\circ} \mathrm{E}, 55^{\circ} \mathrm{N}, 65^{\circ} \mathrm{N}$ ), the SPI correlation between forecasted year $\mathrm{Y}$ and previous year (Y-1) is -0.47 whereas the correlation between the forecasted $\mathrm{Y}$ and two years earlier birch SPI (Y-2) is 0.41 . One of possible ways to formalise the relations is the following:

$\Delta S P I^{r e g}(Y)=\ln (b)+a\left(\Delta S P^{\text {reg }}(Y-2)-\Delta S P I^{\text {reg }}(Y-1)\right)$

Fitting the coefficients $a$ and $b$ for Finland (obs: not for the whole region!), one obtains $\mathrm{a}=0.21$ and $\mathrm{b}=0.97$. The optimal $a$ and $b$ values differ from area to area and country to country but $b$ is usually around 1 and $a$ varies between 0.1 and 0.3 . Areas where mean SPI is low have proven to be difficult. As a result, $b=1.0$ and $a=0.21$ may be taken for the whole Europe, thus providing a rough screening algorithm for the SPI predictions if a few years of pollen observations are available but meteorological data are not straightforward to obtain (a rare occasion).

Performance of the SPI-only model Eq. (4) is usually worse than the scores of the meteo-only model - see examples for a few Finnish stations in (Fig. 5). An exception is the Vaasa station (Fig. 5), which is one of the northern-most sites in the region. That far in the north, the limitations of the plant productivity are the most-severe, so the biology-related amplification of the external stress become so strong that SPI itself contains sufficient amount of information to predict the next-year flowering. As a result, both models that use SPI as (one of) predictor(s) show very high correlation whereas meteo-only model stays behind.

\subsection{Possibilities for further generalization of the models}

The suggested models were made for a large but still limited region in the north of Europe. Since the climatic conditions and plant response to the stress change gradually along north-south and west-east directions, the models score lower in Lithuania and southern Sweden (Fig. $6)$, which delineate the southern border of the region.

\subsubsection{Performance outside the domain}

Outside the region, the model gives poor predictions if temporal correlation is considered (Fig. 7) - but the low-high- season differentiation is still very good (see OR ans MA, Fig. 3). The time series are still quite good for the years with pronounced bi-annual cycle but large errors show up when this cycle breaks down. Such "unusual" years also become more frequent, especially in Brussels, where the bi-annual cycle is practically non-existent. It indicates a presence of some unaccounted factors, which control the SPI in temperate climate.

\subsubsection{Steps towards European model}

Considering the expansion of the models, one needs to involve other parameters, at least the amount of precipitation and winter-time chilling. The principal difficulty will be that the interplay between the governing processes will, most probably, be strongly non-linear and non-additive. In-essence, this study covered the area where the relations between the governing parameters and the SPI are well represented as linear and additive. Noteworthy, the SPI variations correlate between different locations within the region but not with places outside of it. It again points out at non-linear dependencies of the SPI on governing parameters if a wider region is considered.

At the current stage, there are two possibilities for constructing the model for the whole Europe: (i) increase the number of parameters and allow for strong non-linearities in the dependencies (possible, as shown by Ritenberga et al., 2016), (ii) construct different model(s) for Central and Eastern Europe as, for instance, done for the olive season timing forecasting by (Aguilera et al., 2014). Each approach has its pros and contras.

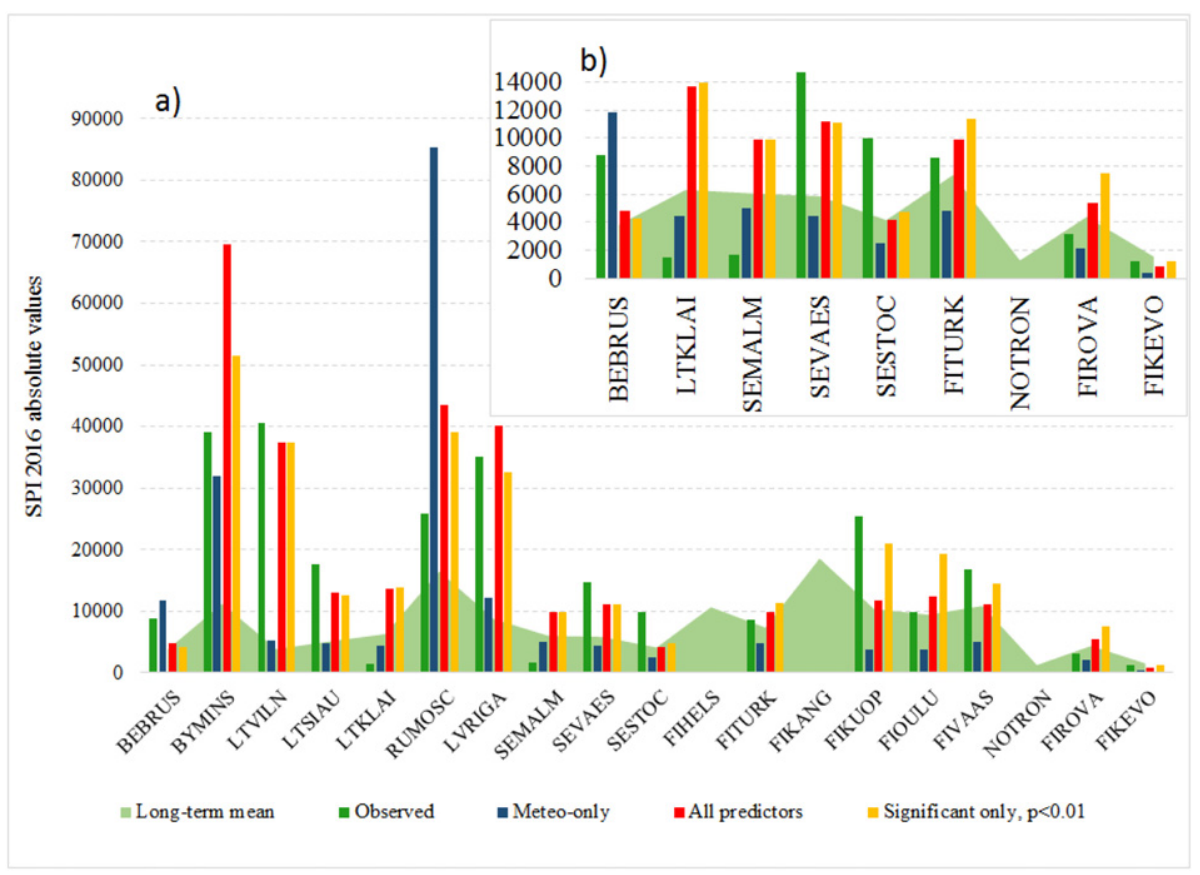

Fig. 4. Comparison of the predicted and observed SPI for the three models presented in Table 3 in 2016 ( $\sum$ pollen/year $\mathrm{m}^{-3}$ ), a) - full data set; b) low SPI sites. 

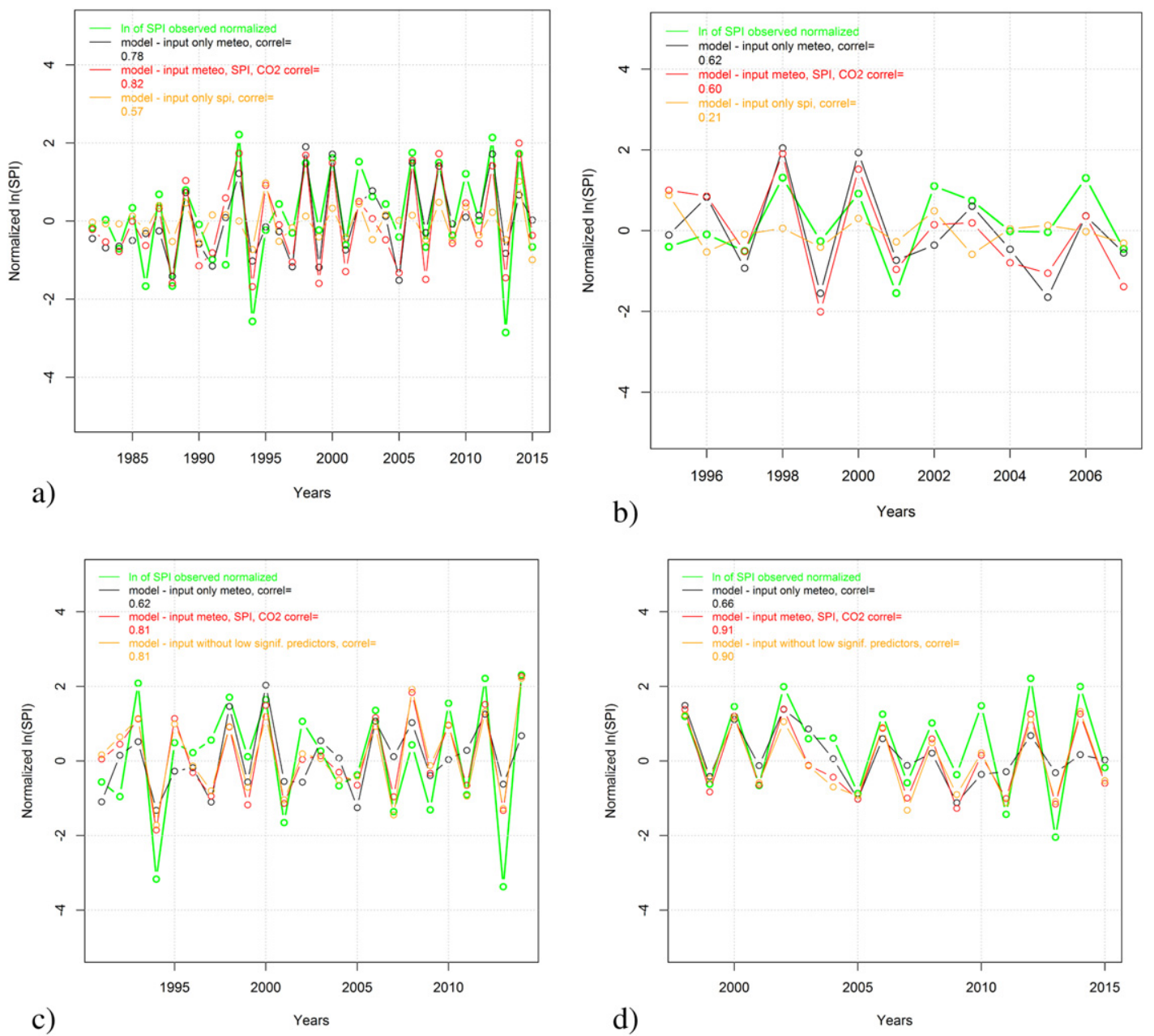

Fig. 5. Comparison of the three models for Finnish stations. Panel: a) Turku; b) Kangasala; c) Helsinki; d) Vaasa.

The first approach, being clearly preferable from the user standpoint, faces a wide variety of interplay of the governing parameters, which have to be identified and quantified. For instance, lack of chilling can both reduce the SPI and shift the season (Hänninen, 1990), whereas very cold winters may have no effect at all (saturation above certain threshold, (Hänninen, 1990)), provoke more intense flowering and seeding (reproduction push), or damage some trees and reduce SPI for several years (damage of the habitat). These and other processes can dominate or be negligible depending on climatic zones, so that their unified consideration will be cumbersome. Finally, expansion will require different treatment of meteorology since the area will be much larger than the synoptic scale, i.e. the homogeneity assumption with regard to the meteorological input will no longer be valid.
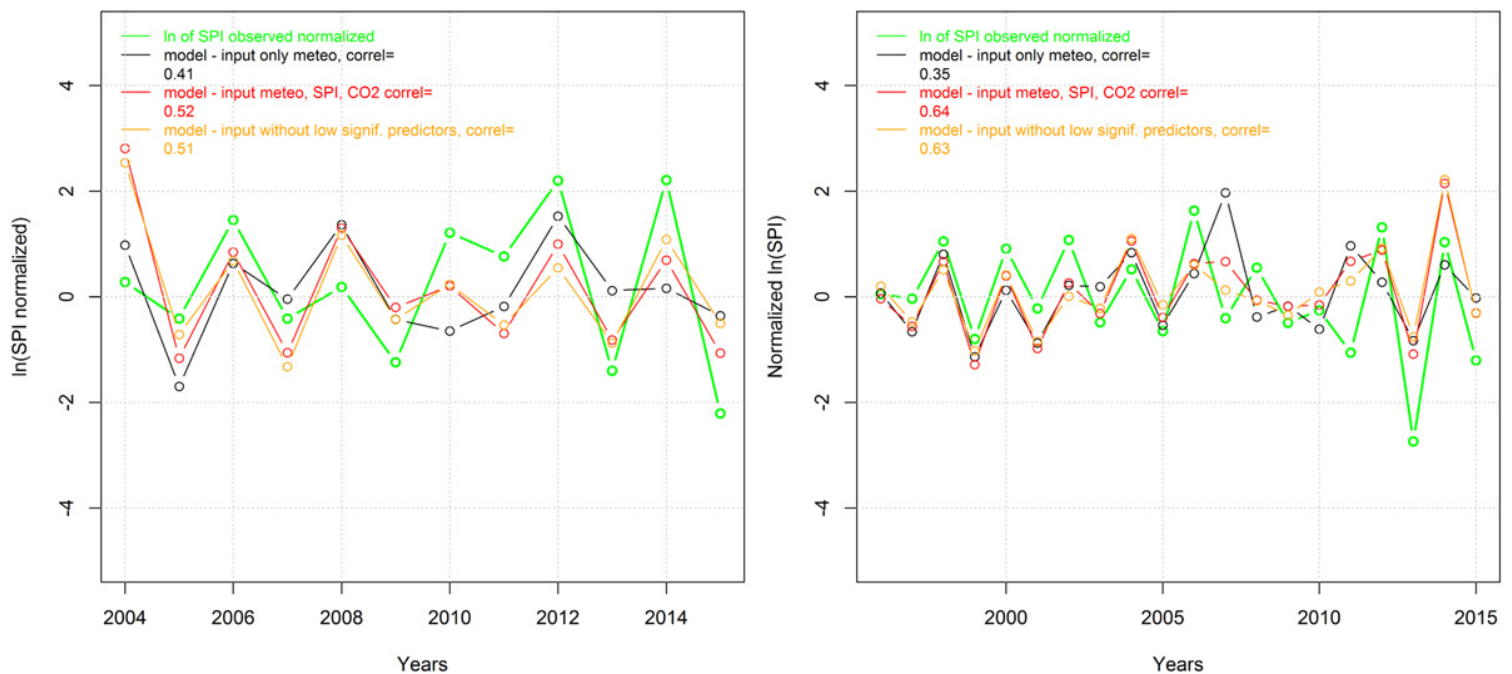

Fig. 6. Model performance in Lithuania (Siauliai) (left-hand panel) and southern Sweden (Vaestervik) (right-hand panel). 

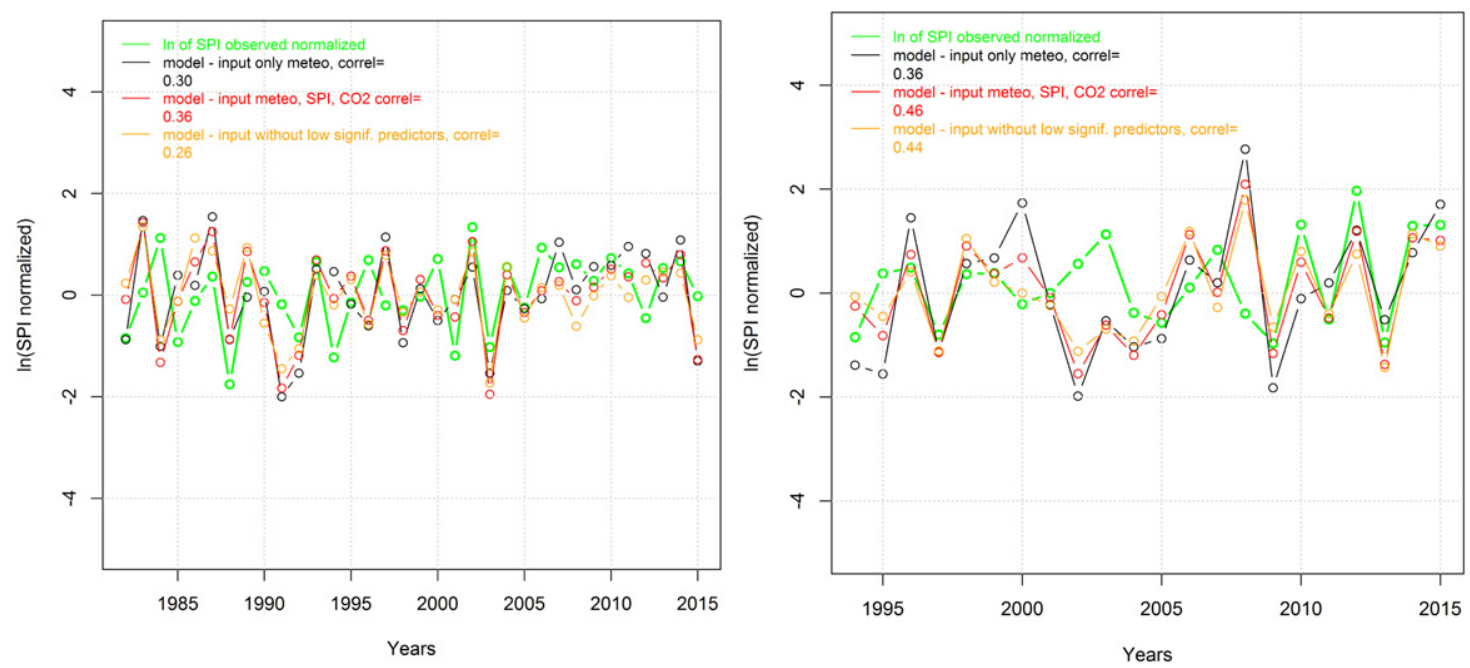

Fig. 7. Examples of the model performance outside the identified region: Brussels (left-hand panel) and Moscow (right-hand panel).

The multi-model approach, albeit being easier in each region, leads to discontinuities of the parameterizations at the borders of the delineated areas, where also none of the models is good. Therefore, it can be recommended only as an intermediate step revealing the governing parameters in each region and suggesting their (linearized) relations, which are then used for development of the unified model.

\section{Conclusions}

We demonstrated that the inter-annual variability of the birch seasonal pollen index SPI is synchronized over large regions of Europe significant correlations at the distances associated with the synoptic spatial scale.

A predictive model was constructed for the region covering Finland, Sweden, and Baltic States, part of Belarus, and, probably, part of Russia and Norway, where the lack of data did not allow for conclusive analysis.

Three models were constructed based on: (i) previous-year meteorology and $\mathrm{CO}_{2}$, (ii) several previous years of the SPI, (iii) combination of the previous-year meteorology, $\mathrm{CO}_{2}$ and the SPI.

The best-performing model based on combination of the meteorological and aerobiological data from the preceding years showed correlation coefficient reaching up to 0.9 and successfully reproduced both bi-annual cycle of the SPI as well as the years when this cycle breaks down. Odds ratio is infinitely high for $50 \%$ of sites inside the region and the fraction of prediction falling within factor of 2 from observations, stays within $40-70 \%$.

Meteo-only model also showed remarkably good prediction skills, which allow its usage in the areas with sparse or no pollen observational network. The model captured the bi-annual cycles and its breaking years, which highlights the key role of meteorology in formation of this cycle. The dynamic range of the variations is however understated by this model, pointing out the importance of the plant response to the meteorological stress.

Supplementary data to this article can be found online at https://doi. org/10.1016/j.scitotenv.2017.09.061.

\section{Acknowledgements}

The study was supported by: performance-based funding of University of Latvia Nr. AAP2016/B041//ZD2016/AZ03 within the "Climate change and sustainable use of natural resources" programme; National Research Program of Latvia LATENERGI 2014.10-4/VPP-1/27; Finnish Academy project APTA 266314 and Copernicus Atmospheric Monitoring Service CAMS; Finish Funding Agency for Innovations (Tekes) project Smart Pollen and Finnish Academy project SAPID.
Authors thank Nickolay Chashnikov for technical help with the model development.

\section{References}

Aguilera, F., Fornaciari, M., Ruiz-Valenzuela, L., Galan, C., Msallem, M., Dhiab, A. Ben, de la Guardia, C.D., del Mar Trigo, M., Bonofiglio, T., Orlandi, F., 2014. Phenological models to predict the main flowering phases of olive (Olea europaea L.) along a latitudinal and longitudinal gradient across the Mediterranean region. Int. J. Biometeorol. 59:629-641. https:// doi.org/10.1007/s00484-014-0876-7.

Albertine, J.M., Manning, W.J., Da Costa, M., Stinson, K.A., Muilenberg, M.L., Rogers, C.A., 2014 Projected carbon dioxide to increase grass pollen and allergen exposure despite higher ozone levels. PLoS One 9:1-6. https://doi.org/10.1371/journal.pone.0111712.

Bastl, K., Kmenta, M., Pessi, A.M., Prank, M., Saarto, A., Sofiev, M., Bergmann, K.C., Buters, J.T.M., Thibaudon, M., Jäger, S., Berger, U., 2016. First comparison of symptom data with allergen content (Bet v 1 and Phl p 5 measurements) and pollen data from four European regions during 2009-2011. Sci. Total Environ. 548-549:229-235. https://doi.org/10.1016/ j.scitotenv.2016.01.014.

Chuine, I., Belmonte, J., 2004. Improving Prophylaxis for Pollen allergies: Predicting the Time Course of the Pollen Load of the Atmosphere of Major Allergenic Plants in France and Spain 43, 65-80. https://doi.org/10.1080/00173130410019163.

Corden, J.M., Stach, A., Millington, W.M., 2002. A comparison of Betula pollen seasons at two European sites; Derby, United Kingdom and Poznan, Poland (1995-1999). Aerobiologia $18,45-53$.

Cunha, M., Ribeiro, H., 2015. Pollen-based predictive modelling of wine production: application to an arid region. Eur. J. Agron. https://doi.org/10.1016/j.eja.2015.10.008.

Dahl, A., Strandhede, S.-O., 1996. Predicting the intensity of the birch pollen season. Aerobiologia 12, 97-106.

Dahl, Å., Galan, C., Hajkova, L., Pauling, A., Sikoparija, B., Smith, M., Vokou, D., 2013. The onset, course and intensity of the pollen season. In: Sofiev, M., Bergmann, K.-C. (Eds.), Allergenic Pollen. A Review of the Production, Release, Distribution and Health Impacts. Springer, Dordrecht, Heidelberg New York, London:pp. 29-70 https://doi.org/10.1007/978-94-007-4881-1.

D'Amato, G., Cecchi, L., Bonini, S., Nunes, C., Liccardi, G., Popov, T., Cauwenberge, P. Van, 2007. Allergenic pollen and pollen allergy in Europe. Allergy:976-990 https://doi.org/10.1111/ j.1398-9995.2007.01393.x.

Dee, D.P., Uppala, S.M., Simmons, A.J., Berrisford, P., Poli, P., Kobayashi, S., Andrae, U., Balmaseda, M.A., Balsamo, G., Bauer, P., Bechtold, P., Beljaars, A.C.M., van de Berg, L., Bidlot, J., Bormann, N., Delsol, C., Dragani, R., Fuentes, M., Geer, A.J., Haimberger, L., Healy, S.B., Hersbach, H., Hólm, E.V., Isaksen, L., Kållberg, P., Köhler, M., Matricardi, M., McNally, A.P., Monge-Sanz, B.M., Morcrette, J.-J., Park, B.-K., Peubey, C., de Rosnay, P., Tavolato, C., Thépaut, J.-N., Vitart, F., 2011. The ERA-interim reanalysis: configuration and performance of the data assimilation system. Q. J. R. Meteorol. Soc. 137:553-597. https://doi.org/10.1002/qj.828.

Detandt, M., Nolard, N., 2000. The fluctuations of the allergenic pollen content of the air in Brussels (1982 to 1997). Aerobiologia 16, 55-61.

Dhiab, A. Ben, Dominguez-vilches, E., Dhiab, A. Ben, Mimoun, M. Ben, Oteros, J., Garcia-mozo, H. 2016. Modeling olive-crop forecasting in Tunisia. https://doi.org/10.1007/s00704-0151726-1.

Galán, C., Smith, M., Thibaudon, M., Frenguelli, G., Oteros, J., Gehrig, R., Berger, U., Clot, B. Brandao, R., 2014. Pollen monitoring: minimum requirements and reproducibility of analysis. Aerobiologia 30:385-395. https://doi.org/10.1007/s10453-014-9335-5.

Garcia-Mozo, H., Yaezel, L., Oteros, J., Galan, C., 2014. Statistical approach to the analysis of olive long-term pollen season trends in southern Spain. Sci. Total Environ. 473-474:103-109. https://doi.org/10.1016/j.scitotenv.2013.11.142.

Grewling, Ł., Jackowiak, B., Nowak, M., Uruska, A., Smith, M., 2012. Variations and trends of birch pollen seasons during 15 years (1996-2010) in relation to weather conditions in Poznan (Western Poland). Grana 51 (4):280-292. https://doi.org/10.1080/00173134.2012.700727.

Hänninen, H., 1990. Modeling bud dormancy release in trees from cool and temperate regions. Acta For. Fenn. 213, 1-47.

Hartmann, D.L., Tank, A.M.G.K., Rusticucci, M., 2013. IPCC Fifth Assessment Report, Climatie Change 2013: The Physical Science Basis. Ipcc AR5. pp. 31-39. 
Hatfield, J.L., Prueger, J.H., 2015. Temperature extremes: effect on plant growth and development. Weather Clim. Extrem. 10:4-10. https://doi.org/10.1016/j.wace.2015.08.001.

Hättestrand, M., Jensen, C., Hallsdóttir, M., Vorren, K.-D., 2008. Modern pollen accumulation rates at the north-western fringe of the European boreal. Rev. Palaeobot. Palynol. 151 90-109. https://doi.org/10.1016/j.revpalbo.2008.03.001.

Hedhly, A., Hormaza, J.I., Herrero, M., 2009. Global warming and sexual plant reproduction. Trends Plant Sci. 14:30-36. https://doi.org/10.1016/j.tplants.2008.11.001.

Helbig, N., Vogel, B., Vogel, H., Fiedler, F., 2004. Numerical modelling of pollen dispersion on the regional scale. Aerobiologia 3, 3-19.

Hirst, J.M., 1954. An automatic volumetric spore trap. Ann. Appl. Biol. 39, 257-265.

Huynen, M., Menne, B., Behrendt, H., Bertollini, R., Bonini, S., Brandao, R., Clot, B., D'Ambrosio, C., De Nuntiis, P., Ebi, K., Emberlin, J., Orbanne, E., Galán, C., Jäger, S., Kovats, S., Mandrioli, P., Martens, P., Menzel, A., Nyenzi, B., Rantio-Lehtimäki, A., Ring, J., Rybnicek, O., TraidlHoffmann, C., Van Vliet, A., Voigt, T., Weiland, S., Wickman, M., 2003. Phenology and Human Health: Allergic Disorders. World Health Organisation.

Jato, V., Rodríguez-Rajo, F.J., Aira, M.J., 2007. Use of phenological and pollen-production data fo interpreting atmospheric birch pollen curves. Ann. Agric. Environ. Med. AAEM 14, 271-280

Ladeau, S.L., Clark, J.S., 2006. Pollen production by Pinus taeda growing in elevated atmospheric $\mathrm{CO}_{2}$. Funct. Ecol. 20:541-547. https://doi.org/10.1111/j.1365-2435.2006.01133x.

Latałowa, M., Mietus, M., Uruska, A., 2002. Seasonal variations in the atmospheric Betula pollen count in Gdansk (southern Baltic coast) in relation to meteorological parameters. Aerobiologia 18, 33-43.

Linsser, G., 1867. Die periodischen Erscheinungen des Pflanzenlebens in ihrem Verhältniss zu den Wärmeerscheinungen. Mem. l'Acad. Imp. d. sc. St Petersbg. XI. pp. 1-44.

Masaka, K., 2001. Modelling the masting behaviour of Betula platyphylla var. japonica using the resource budget model. Ann. Bot. 88:1049-1055. https://doi.org/10.1006/anbo.2001.1547.

Myszkowska, D., 2013. Prediction of the birch pollen season characteristics in Cracow, Polan using an 18-year data series. Aerobiologia 29:31-44. https://doi.org/10.1007/s10453-012 9260-4

Orlandi, F., Romano, B., Fornaciari, M., 2005. Relationship between pollen emission and fruit production in olive (Olea europaea L.). Grana 44:98-103. https://doi.org/10.1080/ 00173130510010440

Oteros, J., Garcia-Mozo, H., Hervas, C., Galan, C., 2013. Biometeorological and autoregressive indices for predicting olive pollen intensity biometeorological and autoregressive indices for predicting olive pollen intensity. Int. J. Biometeorol. 307-316. https://doi.org/10.1007/ s00484-012-0555-5.

Prank, M., Chapman, D.S., Bullock, J.M., Belmonte, J., Berger, U., Dahl, A., Jäger, S., Kovtunenko, I, Magyar, D. Niemelä, S., Rantio-Lehtimäki, A, Rodinkova, V., Sauliene, I., Severova, E. Sikoparija, B., Sofiev, M., 2013. An operational model for forecasting ragweed pollen release and dispersion in Europe. Agric. For. Meteorol. 182-183:43-53. https://doi.org/10.1016/ j.agrformet.2013.08.003.

Prasad, P.V. Craufurd, P.Q Summerfield, 1999. Fruit number in relation to pollen production and viability in groundnut exposed to short episodes of heat stress. Ann. Bot. 84:381-386. https://doi.org/10.1006/anbo.1999.0926.

Puc, M., 2012. Artificial neural network model of the relationship between Betula pollen and meteorological factors in Szczecin (Poland). Int. J. Biometeorol. 56:395-401. https:/ doi.org/10.1007/s00484-011-0446-1.

Ranta, H., Satri, P., 2007. Synchronized inter-annual fluctuation of flowering intensity affects the exposure to allergenic tree pollen in North Europe. Grana 46:274-284. https://doi.org/ $10.1080 / 00173130701653079$

Ranta, H., Oksanen, A., Hokkanen, T., Bondestam, K., Heino, S., 2005. Masting by Betula-species: applying the resource budget model to north European data sets. Int. J. Biometeorol. 49: 146-151. https://doi.org/10.1007/s00484-004-0228-0.

Ranta, H., Hokkanen, T., Linkosalo, T., Laukkanen, L., Bondestam, K., Oksanen, A., 2008. Male flowering of birch: spatial synchronization, year-to-year variation and relation of catkin numbers and airborne pollen counts. For. Ecol. Manag. 255:643-650. https://doi.org/ 10.1016/j.foreco.2007.09.040.

Ritenberga, O., Sofiev, M., Kirillova, V., Kalnina, L., Genikhovich, E., 2016. Statistical modelling of non-stationary processes of atmospheric pollution from natural sources: example of birch pollen. Agric. For. Meteorol. 226-227:96-107. https://doi.org/10.1016/ j.agrformet.2016.05.016

Šaulienė, I., Šukienè, L., Severova, E., Kalnina, L., 2014. Comparison of Alnus, Corylus, Betula pollen seasons in Riga, Moscow and Vilnius. Aerobiologia 30:423-433. https://doi.org/10.1007/ s10453-014-9341-7.

Severova, E., Volkova, O., 2016. Variations and trends of Betula pollen seasons in Moscow (Russia) in relation to meteorological parameters. Aerobiologia https://doi.org/10.1007/ s10453-016-9460-4.

Siljamo, P., Sofiev, M., Filatova, E., Grewling, L., Jäger, S., Khoreva, E., Linkosalo, T., Ortega Jimenez S., Ranta, H., Rantio-Lehtimäki, A., Svetlov, A., Veriankaite, L., Yakovleva, E., Kukkonen, J. 2012. A numerical model of birch pollen emission and dispersion in the atmosphere.
Model evaluation and sensitivity analysis. Int. J. Biometeorol. https://doi.org/10.1007/ s00484-012-0539-5.

Simmons, A.J., Willett, K.M., Jones, P.D., Thorne, P.W., Dee, D.P., 2010. Low-frequency variations in surface atmospheric humidity, temperature, and precipitation: inferences from reanalyses and monthly gridded observational data sets. J. Geophys. Res. Atmos. 115: 1-21. https://doi.org/10.1029/2009JD012442.

Sofiev, M., 2016. On impact of transport conditions on variability of the seasonal pollen index. Aerobiologia:1-13 https://doi.org/10.1007/s10453-016-9459-x.

Sofiev, M., Siljamo, P., Ranta, H., Rantio-Lehtimaki, A., 2006. Towards numerical forecasting of long-range air transport of birch pollen: theoretical considerations and a feasibility study. Int. J. Biometeorol. 50:392-402. https://doi.org/10.1007/s00484-006-0027-x.

Sofiev, M., Siljamo, P., Ranta, H., Linkosalo, T., Jaeger, S., Rasmussen, A., Rantio-Lehtimaki, A., Severova, E., Kukkonen, J., 2012. A numerical model of birch pollen emission and dispersion in the atmosphere. Description of the emission module. Int. J. Biometeorol. https://doi.org/ 10.1007/s00484-012-0532-z

Spieksma, F.T.M., Emberlin, J.C., Hjelmroos, M., Jäger, S., 1995. Atmospheric birch (Betula) pollen in Europe: trends and fluctuations in annual quantities and the starting dates of the seasons atmospheric birch (Betula) pollen in Europe: trends and fluctuations in annual quantities and the starting dates of the. Grana 34:51-57. https://doi.org/10.1080/ 00173139509429033

Spieksma, F.T.M., Corden, J.M., Detandt, M., Millington, W.M., Nikkels, H., Nolard, N., Schoenmakers, C.H.H., Wachter, R., de Weger, L.A., Willems, R., Emberlin, J., 2003. Quantitative trends in annual totals of five common airborne pollen types (Betula, Quercus, Poaceae, Urtica, and Artemisia), at five pollen-monitoring stations in western Europe. Aerobiologia 19:171-184. https://doi.org/10.1023/B:AERO.0000006528.37447.15.

Stach, A., Smith, M., Prieto Baena, J.C., Emberlin, J., 2008. Long-term and short-term forecast models for Poaceae (grass) pollen in Poznań, Poland, constructed using regression analysis. Environ. Exp. Bot. 62:323-332. https://doi.org/10.1016/j.envexpbot.2007.10.005.

Stckli, R., Rutishauser, T., Baker, I., Liniger, M.A., Denning, A.S., 2011. A global reanalysis of vegetation phenology. J. Geophys. Res. Biogeosci. 116:1-19. https://doi.org/10.1029/ 2010JG001545.

Storkey, J., Stratonovitch, P., Storkey, J., Stratonovitch, P., Chapman, D.S., Vidotto, F., Semenov, M.A., 2014. A process-based approach to predicting the effect of climate change on the distribution of an invasive allergenic plant in Europe a process-based approach to predicting the effect of climate change on the distribution of an invasive allergenic plant in Eu. PLoS One:1-7 https://doi.org/10.1371/journal.pone.0088156.

Toro, F., Recio, M., Trigo, M.D.M., Cabezudo, B., 1998. Predictive models in aerobiology: data transformation. Aerobiologia 14, 179-184.

Veriankaitè, L., Siljamo, P., Sofiev, M., Šaulienė, I., Kukkonen, J., 2009. Modelling analysis of source regions of long-range transported birch pollen that influences allergenic seasons in Lithuania. Aerobiologia 26:47-62. https://doi.org/10.1007/s10453-009-9142-6.

Williams, J.W., Gonzales, L.M., Kaplan, J.O., 2008. Leaf area index for northern and eastern North America at the Last Glacial Maximum: a data-model comparison. Glob. Ecol. Biogeogr. 17: 122-134. https://doi.org/10.1111/j.1466-8238.2007.00349.x.

Yli-Panula, E., Fekedulegn, D.B., Green, B.J., Ranta, H., 2009. Analysis of airborne Betula pollen in Finland; a 31-year perspective. Int. J. Environ. Res. Publ. Health 6:1706-1723. https:// doi.org/10.3390/ijerph6061706.

Zhang, Y., Isukapalli, S., Bielory, L., Georgopoulos, P., 2013. Bayesian analysis of climate change effects on observed and projected airborne levels of Birch pollen. Atmos. Environ. 68: 64-73. https://doi.org/10.1016/j.atmosenv.2012.11.028.

Zhang, Y, Bielory, L., Georgopoulos, P.G, 2014. Climate change effect on Betula (birch) and Ouercus (oak) pollen seasons in the United States. Int. J. Biometeorol. 58:909-919. https://doi.org/10.1007/s00484-013-0674-7.

Zhang, Y., Bielory, L., Mi, Zh., Cai, T., Robock, A., Georgopoulos, P., 2015. Allergelnic pollen season variations in the past two decades under changing climate in the United States. Glob. Chang. Biol. 21:1581-1589. https://doi.org/10.1111/geb.12755.

Ziello, C., Sparks, T.H., Estrella, N., Belmonte, J., Bergmann, K.C., Bucher, E., Brighetti, M.A., Damialis, A., Dedandt, M., Galan, C., Gehrig, R., Grewling, L., Guiterrez Bustillo, A.M., Hallsdottir, M., Kockhans-Bieda, C., Linares, C., Myskowska, D., Paldy, A., Sanches, A., Smith, M., Thibaudon, M., Travaglini, A., Uruska, A., Valencia Berra, R.M., Vokou, D. Wacher, R., de Weger, L.A., Menzel, A., 2012. Changes to airborne pollen counts across Europe. PLoS One 7 (4). https://doi.org/10.1371/journal.pone.0034076.

Ziska, L.H., Beggs, P.J., 2012. Anthropogenic climate change and allergen exposure: the role of plant biology. J. Allergy Clin. Immunol. 129:27-32. https://doi.org/10.1016/ j.jaci.2011.10.032.

Ziska, L.H., Ghannoum, O., Baker, J.T., Conroy, J., Bunce, J.A., 2001. A global perspective of ground level, ambient carbon dioxide for assessing the response of plants to atmospheric $\mathrm{CO}_{2}$. Glob. Chang. Biol. 7, 789-796. 